Recepción: 09 / 09 / 2016

Aceptación: 15 / 03 / 2017

Publicación: 29 / 04 / 2017

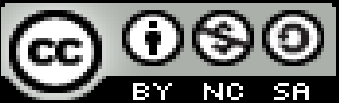

Ciencias económicas y empresariales

Artículo de investigación

\title{
Economía y Cultura. Dos procesos sociales que permiten el enriquecimiento de las relaciones humanas
}

Economy and Culture. Two social processes that allow the enrichment of human relations

Economia e Cultura. Dois processos sociais que permitem o enriquecimento das relações humanas

\author{
Gladys del C. Salas-Lara' \\ carmitasalas@hotmail.com \\ Jamile K. Maldonado-Santana ${ }^{\text {II }}$ \\ jaka2477@hotmail.com \\ Mariuxi A. Guijarro-Cagua ${ }^{\text {II }}$ \\ mariuxiguijarro@gmail.com
}

Correspondencia: carmitasalas@ hotmail.com

'Magister en Tributación y Finanzas, Doctora en Contabilidad y Auditoría, Licenciada en Contabilidad y Auditoría Contadora Publica, Tecnóloga en Gestión Financiera, Docente de la Universidad San Gregorio de Portoviejo, Portoviejo, Ecuador.

"Magister en Administración de Empresas, Ingeniera en, Administración de Empresas Públicas, Docente de la Universidad Técnica "Luis Vargas Torres" de Esmeraldas, Esmeraldas, Ecuador.

"'Máster en Administración de Empresas, Ingeniera En Sistemas, Docente de la Universidad Luis Vargas Torres de Esmeraldas, Esmeraldas, Ecuador. 


\title{
Resumen
}

La cultura en el contexto de la comunidad es un elemento que estimula el desarrollo en todas sus dimensiones. Sería oportuno reflexionar sobre las ventajas que aporta la incorporación directa de la cultura a las distintas áreas estratégicas del desarrollo económico. Por tal razón, la actividad económica, como forma de actividad cultural, debe tributar a la satisfacción de las necesidades materiales y espirituales de la sociedad. Cada una de ellas está orientada hacia la búsqueda del desarrollo humano. En el presente trabajo se reflexiona en torno a tales cuestiones.

Palabras clave: economía; cultura; relaciones humanas; comunidad.

\begin{abstract}
Culture in the context of the community is an element that stimulates the development in all its dimensions. It would be appropriate to reflect on the advantages that the direct incorporation of culture brings to the different strategic areas of economic development. For this reason, economic activity, as a form of cultural activity, should tax the satisfaction of the material and spiritual needs of society. Each of them is oriented towards the pursuit of human development. In the present work is reflected on such questions.
\end{abstract}

Keywords: economy; culture; human relations; community.

\section{Introducción}

Para analizar la correlación que se establece entre la economía y la cultura en el entramado de relaciones sociales, es necesario partir de la comprensión del presupuesto teórico de Marx, quien de forma muy acertada explicó, que los hombres en el proceso de producción social de su vida, establecen relaciones de producción que van a determinar la estructura económica de la sociedad, base real sobre la que se levanta la superestructura y a la que corresponden todas las formas de la conciencia social (Marx y Engels, 1979: 519).

La cultura y la economía son procesos resultantes de la actividad práctico - transformadora de los hombres, por lo que no es posible analizarlos como dos momentos separados. La cultura puede asumirse como un conjunto de ciertos modos de vida aprendidos, y de creaciones humanas que van a caracterizar a una determinada sociedad (Berovides 2005: 8). Por tal razón, la actividad económica, como forma de actividad cultural, debe tributar a la satisfacción de las necesidades 
materiales y espirituales de la sociedad. Cada una de ella está orientada hacia la búsqueda del desarrollo humano.

\section{Desarrollo}

Para adentrarnos en el análisis de la relación que se establece entre la Cultura y la Economía como dos procesos sociales, que permiten el enriquecimiento de las relaciones humanas, es necesario partir del presupuesto teórico que ofrece Max-Neef, quien asume que las necesidades humanas constituyen una unidad funcional donde se conjuga el nivel de conocimientos, experiencias, las actitudes, las conductas y las exigencias sociales del sujeto; donde cada uno de estos momentos se expresan en la actividad práctica transformadora (Max-Neef, 1993).

Lo anterior permite dilucidar que el sujeto social a lo largo de su historia se ha manifestado a través de las necesidades, ya sean materiales o espirituales. En tal sentido la Cultura y la Economía en su relación dialéctica constituyen los vehículos a través de los cuales encuentran una expresión real.

Sin embargo, aún prevalece en el discurso de muchos cientistas sociales, la tendencia a limitar la cultura a su fin clásico, es decir, educar al hombre para que utilice de la mejor forma posible la producción material, negando en cierto modo el impacto de ésta sobre la vida económica de la sociedad.

Sería oportuno reflexionar sobre las ventajas que aporta la incorporación directa de la Cultura a las distintas áreas estratégicas del desarrollo económico. Cuando se analiza la consonancia que existe entre la economía y la cultura se realiza desde una doble perspectiva, es decir desde la microeconomía, donde se visualiza el producto artístico, su oferta y demanda; y la macroeconómica, donde se contempla la participación de la cultura como sector productivo en las economías nacionales.

Son muchos los ejemplos que se pudieran ilustrar, para una mejor compresión de la importancia cultural para el desarrollo económico, tal es el caso del Festival del Caribe en Santiago de Cuba, El Festival del Cine Pobre en Gibara Holguín, el turismo nacional e internacional; en ese orden se puede destacar como la cultura ha recuperado un espacio social, llegando a formar parte del centro de la economía, cuyo objetivo comercial básico son los recursos culturales. 
Al analizar la cultura y la economía como sistema en una sociedad determinada, permite entender cómo los seres humanos usan el mundo material no sólo para satisfacer sus necesidades económicas, sino también para expresarse culturalmente, pues cada una depende de un conjunto de actividades que garanticen de forma sistemática el mantenimiento de las necesidades individuales y grupales de los seres humanos, hacemos referencia a los alimentos y otros bienes y servicios indispensables.

La cultura y la economía son dos procesos resultantes de las relaciones que establecen los hombres en la sociedad, ambos son productos de la creación humana y responden a un contexto histórico-cultural concreto, donde solo cambia la manera y los medios para satisfacer las necesidades materiales y espirituales, sin desligarse de la experiencia socialmente elaborada.

Esta concepción desmonta en cierta medida el discurso tradicional; ha quedado demostrado que el crecimiento económico no es únicamente fruto del conocimiento científico y tecnológico, sino también de la cultura. Lo anterior permite explicar cómo toda la producción material tiene su fundamento en la cultura y viceversa. Podría decirse que la economía es a la vez un producto y un productor cultural. Al ser la economía culturalmente construida, no sólo aparece vinculada a la producción de bienes materiales, a su intercambio y a su consumo, sino también, a la producción de valores culturales.

La relación entre la cultura y la economía se entrelaza a partir de una interdependencia donde los factores culturales contribuyen de forma significativa en el proceso de desarrollo de la actividad económica y donde a su vez, la economía forma parte del proceso cultural de generación e innovación de nuevos conocimientos.

Aunque se analizan ambos procesos en su relación sistémica, es preciso considerar que la producción de bienes culturales, en su gran mayoría, requiere de recursos económicos. Lo anterior no quiere decir que todos los productos culturales son vendidos y distribuidos en una economía de mercado. Sin embargo, todas las cosas producidas, intercambiadas y consumidas por el hombre, son enfocadas desde un ámbito social y cultural.

No se debe pasar por alto que todo producto resultante de la actividad humana tiene un significado cultural y un valor económico. Por ejemplo, las obras de artes, las obras literarias, la 
visita a los museos, diseño y moda, las artesanías, la comida, las industrias culturales, eventos culturales.

Otro ejemplo del factor cultural como instrumento para regenerar la actividad económica local es la construcción del complejo cultural "La Alameda" en Santiago de Cuba, el cual revivió el sector comercial e industrial de esa ciudad, mejorando no solo el entorno urbano, sino ofreciendo nuevos servicios para el disfrute de la población, donde existe una promoción constante de actividades culturales y nuevos espacios comerciales.

\section{Aproximación al estudio de la Cultura y la Economía desde el contexto comunitario}

La correlación existente entre la cultura y la economía, analizada desde el contexto comunitario, sugiere un estudio a partir de los múltiples aspectos presentes en la cultura de cada comunidad, en el sentido que puede generar aportes decisivos para su desarrollo cultural y económico. Es, por tanto, una fuente de sabiduría acumulada, establece mecanismos que le permiten tener potencial y conducir su vida de manera productiva y creativa de acuerdo a sus necesidades e intereses.

La cultura en el contexto de la comunidad es un elemento que estimula el desarrollo en todas sus dimensiones, al poseer un alto capital creativo, el cual se encuentra inmerso entre sus miembros. En una comunidad, el aspecto económico representa la forma en que los actores sociales convierten la materia prima en bienes consumibles, mientras que la cultura constituye la herramienta a través de la cual se logra transformar la actividad humana en relaciones sociales productivas.

Se puede decir que tanto la cultura como la economía son procesos dentro de los cuales la comunidad despierta una cierta creencia en sus capacidades, por lo que se proponen retos y deciden unirse para su logro. Partiendo desde la filosofía de que la confianza se nutre con la participación, podemos destacar algunos elementos que constituyen a su fortalecimiento: conectividad entre los miembros de la comunidad, tolerancia ante la diversidad, sentimiento de apego y orgullo por los orígenes de los miembros de la comunidad, todo fruto del trabajo como grupo incentiva la educación comunitaria. 
Como último aspecto señalar que la participación activa y organizada de los miembros de las comunidades es esencial para lograr asentar las bases de la sostenibilidad y del bienestar social. No hay duda de que los valores que son aportados por sus comunitarios pueden incidir fuertemente en su desarrollo económico y cultural.

\section{Conclusiones}

Tras analizar los conceptos de cultura y economía en su relación dialéctica, como procesos que permiten el enriquecimiento de las relaciones humanas, es posible decir que el hombre no puede vivir sin cultura ni economía, pues ellas constituyen requisitos esenciales para el desarrollo de la vida material y espiritual.

La cultura y la economía son procesos que potencian la cohesión social, estimulan las aspiraciones colectivas e individuales. Por lo que no deben ser entendidos como algo distinto, sino como un espacio en donde materializan todas las aspiraciones, deseos, conocimientos, saberes, donde todo lo que se produce y circula es resultado de la actividad prácticotransformadora de los seres humanos.

La cultura es reconocida como una importante dimensión de la Economía en términos de producción y consumo, permite la compresión de sus nuevas formas de comportamiento social, donde se reflejan los principios ideológicos, éticos y morales que coexisten dentro de cada sociedad. De esta manera la cultura ha dejado de ser un elemento aislado de la esfera económica, política y social, y se ha convertido en un pilar que refleja las fortalezas y debilidades de cada sociedad.

\section{Referencias bibliográficas}

Aguileta L. Iñaki. (2000) Cultura y Ciudad: manual de política cultural y municipal. España.TREA.

Ariztía, Tomás. (2014) "Cultura y economía: itinerario de dos conceptos". Plataforma de la Sección Observatorio Cultural del Departamento de Estudios del Consejo Nacional de la Cultura y las Arte. (Descargado de Internet mayo de 2016). 
Ávila Álvarez, M. Antonia. (2001) "La economía de la cultura ¿Una construcción reciente?" ICE, Revista de Economía, No 792. pág. 9-30.

Berovides Álvarez V. (2009) Genoma, cultura y evolución humana. La Habana: Editorial Científico-Técnica.

Furio, Elies. (2006) Economía y cultura. https://halshs.archives-ouvertes.fr/halshs (Descargado de Internet mayo de 2016).

Lasuén Sancho, José Ramón. (2006) Cultura y economía. Madrid: Fundación Autor.

Marx C, Engels F. (1986) Obras escogidas. Moscú: Progreso.

Max-Neef M. (1993) Economía descalza. Señales desde el mundo invisible. Montevideo:

Nordan.

Rausell-Köster, Paul. (2004) Economía y cultura, una pareja de hecho. Editorial Promolibro. Valencia.

Throsby, David. (2003) Economía y cultura. España: Editorial Akal. 